\title{
Surgical treatment of endomyocardial fibrosis with preservation of mitral valve
}

\author{
UNNIKRISHNAN NAIR, TOM EVANS, DAVID OAKLEY \\ From the Division of Cardiovascular Diseases, Royal Postgraduate Medical School, \\ Du Cane Road, London
}

SUMMARY A 48-year-old Kenyan African, who presented with a history of coronary and cerebral embolism, was found to have endomyocardial fibrosis of the left ventricle. It proved possible to remove all diseased tissue at operation, and at the same time to preserve the mitral valve. It is important to inspect the mitral valve from both the atrial and ventricular aspects so that the valve can be spared, if it is not involved in the disease process. The choice of transatrial of transventricular surgical approach for the removal of pathological tissue may depend on whether or not the mitral valve requires replacement.

In the disorder of unknown aetiology known as endomyocardial fibrosis (Bedford and Konstam, 1946) surgical treatment may be required. This was first carried out successfully on the left ventricle by Lepley et al. (1974). In published cases, it has always been necessary to replace the mitral valve when left ventricular lesions have been surgically resected. We report an early case in which we were able to preserve the mitral valve apparatus, and describe the technique that permitted this to be achieved.

\section{Case report}

A 48-year-old Kenyan African presented with a well-documented history of acute anterior myocardial infarction in October 1973. After this he had occasional dyspnoea and angina pectoris and in March 1977 a transient left hemiparesis.

On examination in July 1977 he looked well; the pulse was regular at 70 beats per minute and the blood pressure was $130 / 80 \mathrm{mmHg}$. The venous pressure was not raised and the left ventricular impulse was normal. There was a soft midsystolic murmur at the apex and there were quiet third and fourth heart sounds. The rest of the physical examination was normal.

The electrocardiogram showed broad $P$ waves, left axis deviation, right bundle-branch block, and deep $Q$ waves in V1 to V5; there was also $T$ wave inversion without $S T$ elevation in aVL and V1 to V4. A chest $x$-ray film showed a bulge on the left border of the heart. Haemoglobin and white cell

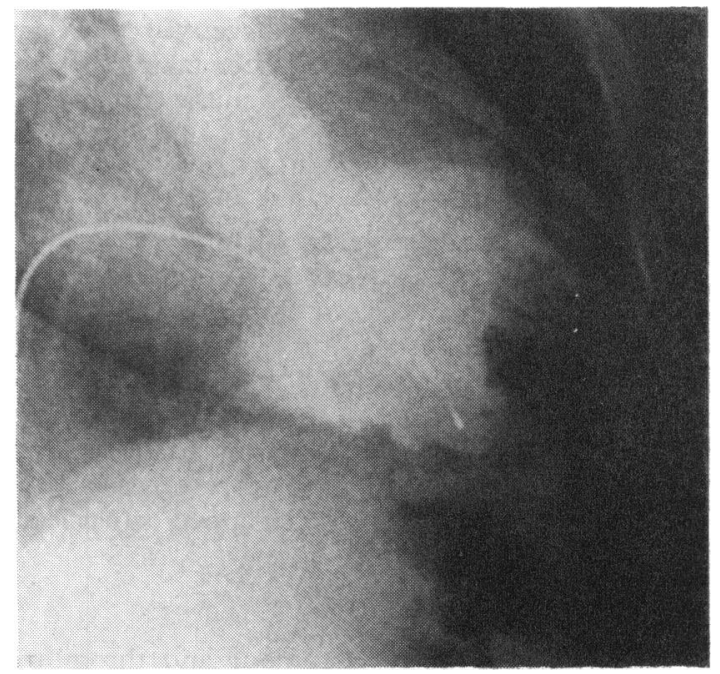

Fig. Left ventriculogram $\left(30^{\circ} \mathrm{RAO}\right)$ showing apical filling defect.

count were normal. Tests for auto antibodies to nuclear protein, smooth muscle, reticulin, and mitrochondria were negative. Blood urea, electrolytes, and liver function tests were normal. At cardiac catheterisation, the left ventricular enddiastolic pressure was $30 \mathrm{mmHg}$ and the left ventricular angiogram showed a large filling defect at the apex (Fig.), with anterior dyskinesia but no abnormality of the mitral valve. Coronary arteriograms were normal.

A provisional diagnosis of endomyocardial 
fibrosis was made, but because of the uncertainty about the precise diagnosis, and the possibility that the transient hemiplegia was the result of embolisation of mural thrombus, operation was advised. This was carried out under cardiopulmonary bypass and hypothermia $\left(30^{\circ} \mathrm{C}\right)$ by Professor H. H. Bentall. The external appearance of the fat-laden apex was normal, but an area of fibrosis $5 \times 5 \mathrm{~cm}$ could be felt beneath it. The mitral valve was normal on inspection through the left atrium. With the aorta cross-clamped, the left ventricular apex was opened by a curved incision. The fibrous tissue, which was $1.5 \mathrm{~cm}$ thick at its centre and thinner towards the periphery, was loosely attached to the underlying myocardium, providing a good plane of cleavage. Thrombus was loosely attached to the endocardial aspect of the fibrous tissue. There was a gap of about $1 \mathrm{~cm}$ between the edge of the fibrosis and the base of the papillary muscles, and no skip lesions. The diseased area was dissected off completely leaving both papillary muscles intact. The ventriculotomy was closed and the bypass terminated.

After the operation the systolic murmur was no longer audible. He made an uneventful recovery and was discharged two weeks later taking aspirin ( $600 \mathrm{mg}$ daily). When he was seen in the out-patient clinic 12 months later, he was well and symptom free, and it was considered unjustified to repeat the angiogram.

Histological examination (Dr J. Hoffa) showed the characteristic changes of endomyocardial fibrosis. There was partially organised blood clot with fibrin and dilated capillaries on the endocardial surface and also young fibroblasts and macrophages. Deep to this layer there was a broad zone of acellular hyalinised fibrous tissue. Adjacent to the myocardium the fibrous tissue was more cellular with some dilated vessels which entrapped superficial myocardial fibres.

\section{Discussion}

In this patient myocardial tumour and thrombus overlying previous infarct were considered in the differential diagnosis. Tumour seemed unlikely in the absence of a pathological circulation in the angiogram. The extensive myocardial infarct could not be attributed to coronary atherosclerosis in the presence of a normal coronary arteriogram, and was probably the result of coronary embolus. In addition, the hemiplegia was best explained by cerebral embolism. The systolic murmur was probably caused by papillary muscle dysfunction which was corrected by the operation. The operation was carried out because of the uncertainty about the precise diagnosis and the fear of further emboli.
The exact cause of endomyocardial fibrosis remains uncertain. The right ventricle is more frequently involved than the left (Shillingford and Somers, 1961) and the apex and inflow tracts of the ventricles are predominantly affected (Davies and Ball, 1955; Shaper, 1972): the atrioventricular valves usually become regurgitant because fibrosis binds the papillary muscles to the endocardium (FarrerBrown and Tarbit, 1972). Endomyocardial fibrosis of the left ventricle may present with mitral regurgitation, pulmonary hypertension, or systemic embolism, and the preoperative diagnosis depends on angiography. No drugs are known to arrest or reverse this disease; survival after diagnosis varies from 12 days to 12 years, with a mean of two years (D'Arbela et al., 1972).

Several further reports have appeared since the first successful excision of endomyocardial fibrosis of the left ventricle (Lepley et al., 1974); in all cases, the mitral valve has been replaced. Our case shows that the mitral valve can be preserved if the disease does not involve it. Lesions of the ventricle can be resected through either the left atrium (Dubost et al., 1976) or the left ventricle (Lepley et al., 1974). Using the transatrial approach the mitral apparatus is excised as the first step. The technical advantage of this approach is the ease of inserting sutures in the mitral ring from above. It does, however, deprive the surgeon of the opportunity to conserve the mitral valve. The second approach has the advantage that the left ventricular apex and the bases of the papillary muscles are adequately exposed and the mitral valve can be spared when possible. It is, however, less easy to inspect and replace the valve by the ventricular approach. In order to identify those cases in which the mitral valve can be preserved, the valve should be examined from the left atrium, and, if it does not need replacement, the operation should be continued through a left ventriculotomy.

We thank Professor $\mathrm{H} \mathrm{H}$ Bentall, Professor J F Goodwin, and Dr J B O Okanga for permission to report this case.

\section{References}

Bedford, D. E., and Konstam, G. L. S. (1946). Heart failure of unknown origin in Africans. British Heart Fournal, 8, 236-237.

D'Arbela, P. G., Mutazindwa, T., Patel, A. K., and Somers, K. (1972). Survival after first presentation with endomyocardial fibrosis. British Heart fournal, 34, 403-407.

Davies, J. N. P., and Ball, J. D. (1955). The pathology of endomyocardial fibrosis in Uganda. British Heart Fournal, 17, 337-359. 
Dubost, Ch., Maurice, P., Gerbaux, A., Bertrand, E., Rulliere, R., Vial, F., Barrillon, A., Prigent, C., Carpentier, A., and Soyer, R. (1976). The surgical treatment of constrictive fibrous endocarditis. Annals of Surgery, 184, 303-307.

Farrer-Brown, G., and Tarbit, M. H. (1972). Heart valve involvement in endomyocardial fibrosis. British Heart Fournal, 34, 1062-1071.

Lepley, D., jun., Aris, A., Korns, M. E., Walker, J. A., and D'Cunha, R. M. (1974). Endomyocardial fibrosis -a surgical approach. Annals of Thoracic Surgery, 18, 626-633.
Shaper, A. G. (1972). Cardiovascular disease in the tropics-II, endomyocardial fibrosis. British Medical fournal, 3, 743-746.

Shillingford, J. P., and Somers, K. (1961). Clinical and haemodynamic patterns in endomyocardial fibrosis. British Heart Fournal, 23, 433-446.

Requests for reprints to U Nair, Esq., FRCS, Department of Cardiothoracic Surgery, Royal Postgraduate Medical School, Du Cane Road, London W12 0HS. 